\title{
$\checkmark$ Research Square \\ Synthesis of Novel Electrospun Composite Nano Powders of the Quaternary Ti-Al-O-B System
}

\section{Zohreh Ghadimi}

Bu-Ali Sina University: Bu Ali Sina University

Hamid Esfahani ( $\square$ h.esfahani@basu.ac.ir)

Bu-Ali Sina University: Bu Ali Sina University

Yousef Mazaheri

Bu-Ali Sina University: Bu Ali Sina University

\section{Research Article}

Keywords: Aluminum, Borides, Borates, Electrospinning, Nanoparticle, Titanium

Posted Date: September 1st, 2020

DOI: https://doi.org/10.21203/rs.3.rs-68451/v1

License: (1) This work is licensed under a Creative Commons Attribution 4.0 International License. Read Full License 


\title{
Synthesis of Novel Electrospun Composite Nano Powders of the Quaternary Ti-Al-O-B System
}

\author{
Zohreh Ghadimi, Hamid Esfahani ${ }^{1 *}$, Yousef Mazaheri \\ Department of Materials Engineering, Bu-Ali Sina University, Hamedan, Iran, P.O.B: 65178-38695 \\ * Corresponding author: P.O.B: 65178-38695, Tel\&Fax: +98-81-38381601-10, E-mail: h.esfahani@basu.ac.ir
}

\begin{abstract}
In the present work, electrospinning was applied to develop multicomponent oxide, boride, and borate nanostructures in a quaternary Ti-Al-O-B system. Different molar ratios of $\mathrm{B} /(\mathrm{Ti}+\mathrm{Al})$ $(0.8,1.6$, and 2.4) were employed and evaluated. Imaging with the field emission scanning electron microscope (FESEM) and the transmission electron microscope (TEM) revealed that after one hour of thermal treatment at $1100{ }^{\circ} \mathrm{C}$, the hybrid electrospun nanofibers (NFs) in the fibrous platform transformed into nanoparticles (NPs), nano-needles, and nano-whiskers at $\mathrm{B} /(\mathrm{Ti}+\mathrm{Al})$ molar ratios of $0.8,1.6$, and 2.4 , respectively. The binding energies were investigated by X-ray photoelectron spectroscopy (XPS), whereas the phase study was conducted via the X-ray diffraction (XRD) technique. The results confirmed the formation of nanostructured ceramic powder platforms composed of the multiple components, namely oxides (e.g., $\mathrm{B}$ doped $\mathrm{TiO}_{2} ; \mathrm{Al}_{2} \mathrm{O}_{3}$ ), borides $\left(\mathrm{TiB}, \mathrm{TiB}_{2}, \mathrm{Ti}_{2} \mathrm{~B}_{5}\right.$, $\mathrm{TiB}_{12}$, and $\mathrm{AlB}_{2}$ ), and borates $\left(\mathrm{TiBO}_{3} ; \mathrm{Al}_{18} \mathrm{~B}_{4} \mathrm{O}_{33}\right)$. Simultaneous thermal analysis (STA) of the Ti-Al-O-B mats indicated that the borides and borates formed consecutively at temperatures above $800{ }^{\circ} \mathrm{C}$ through reactions involving molten $\mathrm{B}_{2} \mathrm{O}_{3}$. We found that the obtained NPs were well arranged and sintered together throughout the fibers.
\end{abstract}

Keywords: Aluminum; Borides; Borates; Electrospinning; Nanoparticle; Titanium; 


\section{Introduction}

Ceramic particles, due to having desirable physical, chemical, and mechanical properties, are widely used as catalysts, semiconductors, electromagnetics, filtration media, thermal insulators, fillers, and reinforcements [1-3]. Nanostructured ceramics such as nanoparticles (NPs) and nanofibers (NFs) have drawn much attention in particular applications due to their unique properties such as the high surface area to volume ratio, low density, low heat conductivity, high hardness and excellent toughness [4-5]. The development of multicomponent ceramic products from nanostructured oxides, borides, and borates is an efficient solution for overcoming the hardness, corrosion resistance, high melting point, and abrasive requirements of designed systems [7,8]. Thus, a quaternary Ti-Al-O-B system can logically be used for exhibiting outstanding oxides, borides, and borates of titanium and aluminum components on the nanoscale.

Titanium borides have stoichiometric diversity in the forms of $\mathrm{TiB}, \mathrm{TiB}_{2}, \mathrm{Ti}_{3} \mathrm{~B}_{4}, \mathrm{Ti}_{2} \mathrm{~B}_{5}$ as well as $\mathrm{TiB}_{12}[8,9]$. Several routes, such as pack cementation, magnetron sputtering, and selfpropagating high-temperature synthesis (SHS), have been developed to produce the titanium borides as well as titanium borate $\left(\mathrm{TiBO}_{3}\right)$ [10-12]. However, there is one main problem in the Ti-B system for production of some kinds of titanium borides. Some borides (e.g., $\mathrm{Ti}_{2} \mathrm{~B}_{5}$ and $\mathrm{TiB}_{12}$ ) are formed via particular production methods such as SHS [13]. Titanium boride powders have received considerable attention for mechanical applications due to the presence of covalent bonds within the titanium matrix $[14,15]$. The diffusion coefficient of B into the titanium matrix has a significant role in the formation of the specific kind of titanium boride [16]. According to the literature review, by controlling the production reactions in the solidliquid $\mathrm{TiO}_{2}-\mathrm{B}_{2} \mathrm{O}_{3}$ binary system, the desired titanium boride and borate species can be generated [17].

Aluminum borates $\left(\mathrm{Al}_{18} \mathrm{~B}_{4} \mathrm{O}_{33}\right.$ and $\left.\mathrm{Al}_{4} \mathrm{~B}_{2} \mathrm{O}_{9}\right)$ are the main stable phases present in the $\mathrm{Al}_{2} \mathrm{O}_{3}$ $\mathrm{B}_{2} \mathrm{O}_{3}$ binary system. $\mathrm{Al}_{18} \mathrm{~B}_{4} \mathrm{O}_{33}$ is stable until up to $1900{ }^{\circ} \mathrm{C}$ and is generated with lower $\mathrm{B}_{2} \mathrm{O}_{3}$ amounts, whereas $\mathrm{Al}_{4} \mathrm{~B}_{2} \mathrm{O}_{9}$ is produced when more $\mathrm{B}_{2} \mathrm{O}_{3}$ is present and is stable only below $1100{ }^{\circ} \mathrm{C}$ [18]. Aluminum borates have a strong tendency toward taking a needle-like morphology [19]. Production of aluminum borate needles or whiskers occurs between 600 and $800{ }^{\circ} \mathrm{C}$; these products are often utilized in metal alloys for reinforcement, insulation, and improving oxidation resistance [20,21]. It is noteworthy that their application is not limited to metal matrix; Wang et al. [22] utilized the one-dimensional $\mathrm{Al}_{18} \mathrm{~B}_{4} \mathrm{O}_{33}$ as a junction between 
two alumina pieces at high temperatures. The $\mathrm{AlB}_{2}$ powders can also be prepared via the aluminothermy reaction in the $\mathrm{Al}_{2} \mathrm{O}_{3}-\mathrm{B}_{2} \mathrm{O}_{3}$ binary system. This kind of boride can be used to induce oxidation resistance because it is decomposed into $\mathrm{Al}$ and $\mathrm{B}$ at high temperatures [23].

Several routes are available for the preparation of nanostructured ceramic NPs and NFs, including sol-gel, crystallization from molten salts, combustion synthesis, and melt spinning [24-26]. However, the electrospinning method presents a simple and cost-efficient process that yields continuous fibers with average diameters of nano to micrometers [27,28]. In fact, electrospinning has recently facilitated the synthesis of nanocomposite particles and nanostructured thin films [29,30]. There are two approaches toward developing ceramic NFs via the electrospinning procedure: ceramic reagents are either blended as ceramic NPs or dissolved into a polymer solution as ceramic precursors. It should be added that post-heat treatment may regulate the final product as amorphous to highly crystalized ceramic NFs [28]. Dai et al. [31] were the first to attempt the preparation of borate fibers; they simply synthesized the predominating $\mathrm{Al}_{4} \mathrm{~B}_{2} \mathrm{O}_{9}$ species and traces of $\mathrm{Al}_{18} \mathrm{~B}_{4} \mathrm{O}_{33}$ crystals via the electrospinning method. Later, Ozdemir et al. [32] investigated the role of the viscosity of the electrospinning solution for the production of aluminum borate NFs. In another experimentation with the electrospinning technique, Song et al. [33] studied the formation of mullite-type composite NFs in the $\mathrm{Al}_{2} \mathrm{O}_{3}-\mathrm{SiO}_{2}-\mathrm{B}_{2} \mathrm{O}_{3}$ system. Nevertheless, there is a lack of studies regarding the NFs of borides and borates, especially in the ternary $\mathrm{TiO}_{2}-\mathrm{Al}_{2} \mathrm{O}_{3}-\mathrm{B}_{2} \mathrm{O}_{3}$ system.

This study aimed to investigate the potential of the electrospinning procedure in the formation of diverse boride and borate nano-arrays of the quaternary Ti-Al-O-B system. The novelty of this study was the aim of achieving synergetic effects between titanium boride NPs and the aluminum borate nano-whiskers. Since the $\mathrm{B} /(\mathrm{Ti}+\mathrm{Al})$ molar ratio has a significant impact on the physical and mechanical properties of borides [34], an electrospun Ti-Al-O-B powder was first synthesized using a $\mathrm{B} /(\mathrm{Ti}+\mathrm{Al})$ molar ratio of 0.8 . Afterward, Ti-Al-O-B powder samples were developed with two and three times higher boron contents $(\mathrm{B} /(\mathrm{Ti}+\mathrm{Al})$ molar ratios of 1.6 and 2.4, respectively). Finally, a range of analytical experiments was conducted to facilitate an understanding of the mechanisms involved in the formation of the powders.

\section{Materials and Methods}

\subsection{Fabrication of nanofibrous Ti-Al-O-B powders}


The electrospinning method was applied to produce the fibrous Ti-Al-O-B mat. A hybrid electrospinning solution containing the polymer and ceramic reagents was prepared via a twostep process. First, appropriate amounts of aluminum nitrate $\left(\mathrm{Al}\left(\mathrm{NO}_{3}\right)_{3} .9 \mathrm{H}_{2} \mathrm{O}\right.$, Merck-101063), boric acid $\left(\mathrm{H}_{3} \mathrm{BO}_{3}\right.$, Merck-100165), and $\mathrm{TiO}_{2} \mathrm{NPs}$ (PlasmaChem GmbH, P25) were dissolved in $3.5 \mathrm{ml}$ of ethanol $\left(\mathrm{C}_{2} \mathrm{H}_{5} \mathrm{OH}\right.$, Merck-100983), with the $\mathrm{B} /(\mathrm{Ti}+\mathrm{Al})$ molar ratio being set at 0.8 . The solution was stirred for $2 \mathrm{~h}$ at room temperature followed by $45 \mathrm{~min}$ of ultra-sonication to obtain a homogenous solution. Secondly, the $0.6 \mathrm{~g}$ of polyvinylpyrrolidone (PVP, Merck 107443) was dissolved in the mentioned solution by $1 \mathrm{~h}$ of magnetic stirring and $45 \mathrm{~min}$ of ultra-sonication, which gave a clear solution. The hybrid solution was electrospun with high voltage direct current $(25 \mathrm{kV})$. The distance between the aluminum foil and needle syringe was $15 \mathrm{~cm}$, and the feeding rate was kept as $0.2 \mathrm{ml}^{-1}$. After drying at $80^{\circ} \mathrm{C}$ for $24 \mathrm{~h}$, the achieved mat was peeled out for heat treatment at $1100{ }^{\circ} \mathrm{C}$ for $1 \mathrm{~h}$ in air atmosphere. The heating rate was $4.5^{\circ} \mathrm{C} \cdot \mathrm{min}^{-1}$, and the cooling step was carried out slowly in the furnace. To understand the effects of boron content on the composition and morphology of the Ti-Al-O-B mat, the mentioned procedure was repeated with two and three times higher $\mathrm{B} /(\mathrm{Ti}+\mathrm{Al})$ molar ratios. $\mathrm{The} \mathrm{B} /(\mathrm{Ti}+\mathrm{Al})$ molar ratio was changed from 0.8 up to 2.4 by adjusting the level of boric acid in solution. The composition of the electrospinning solution is given in Table 1, along with the sample codes.

\subsection{Characterizations}

The microstructures of the as-spun mats were studied by scanning electron microscopy (SEM, model JEOL JSM 840A). The powders were investigated using a field emission scanning electron microscope (FESEM; model T-Scan) equipped with an energy dispersive X-ray spectrometer (EDS). The ImageJ software (1.38x NIH USA) was applied to calculate the size of fibers and particle diameters. The binding energies of Ti, Al, O, and $\mathrm{B}$ were evaluated by $\mathrm{X}$ ray photoelectron spectroscopy (XPS; model BESTEC) with monochromatic Al Ka radiation $(\mathrm{h} v=1486.7 \mathrm{eV})$. High-resolution scanning was performed with a binding energy of $1 \mathrm{~s}$ for $\mathrm{O}$ and $\mathrm{B}$, and $2 \mathrm{p}$ for Ti and Al. The XPS analysis was carried out under $10^{-10} \mathrm{mbar}$ after sputtering with argon ions. The phase study of powders was conducted by X-ray diffraction technique (XRD; model Philips, PW1730 Xpert; $1^{\circ}$ incidence angle; $\mathrm{k}_{\alpha} \mathrm{Cu} ; \lambda=0.154 \mathrm{~nm}$ ). The X'pert HighScore Plus software (Ver. 2.2b) was used to interpret the phase formation data. The thermal behavior of mats in the range of $25-1000{ }^{\circ} \mathrm{C}$ was studied by thermogravimetry (TG) 
and differential thermal analysis (DTA) with a simultaneous thermal analyzer (STA; model PA Q600). The transmission electron microscope (TEM; model Philips EM208S, $100 \mathrm{kV}$ ) facilitated the high-resolution morphological characterization of the prepared ceramic particles.

\section{Results}

The synthesis of nanofibrous Ti-Al-O-B powders has not been reported before this study. Hence, to evaluate the balance of the precursors in the hybrid electrospun solution, the sample with a 0.8 molar ratio of $\mathrm{B} /(\mathrm{Ti}+\mathrm{Al})$ was synthesized. The micrographs of the electrospun nanofibrous TAOB-0.8 mat before and after calcination are displayed in Fig. 1 (a and b). As seen, straight fibers without beads were formed via the electrospinning procedure. The average diameter of the hybrid fibers was $233 \pm 16 \mathrm{~nm}$, providing an appropriate platform for the synthesis of nanostructured ceramic Ti-Al-O-B products. The results showed that the hybrid straight fibers transformed into ceramic particles arranged into a fibrous structure. The average sizes of the particles and fibers were $94 \pm 41$ and $217 \pm 39 \mathrm{~nm}$, respectively. The findings confirmed that a nanostructured ceramic powder was synthesized via the electrospinning method.

To understand the intra-molecular bonds within the developed powder, XPS spectra were obtained concerning to the $\mathrm{Ti}, \mathrm{Al}, \mathrm{O}$, and B elements. The spectra are shown in Fig. 2 confirm the presence of the $\mathrm{Ti}, \mathrm{Al}, \mathrm{O}$, and $\mathrm{B}$ elements inside the ceramic powder. The Ti2p spectrum displays two main $2 \mathrm{p}_{3 / 2}$ and $2 \mathrm{p}_{1 / 2}$ peaks, corresponding with the Ti binding energy values of 458.4 and $464.2 \mathrm{eV}$, respectively. By de-convolution of the Ti2p spectra, it was found that the $2 p_{3 / 2}$ and $2 p_{1 / 2}$ peaks each consisted of three sub-peaks: Ti-O, Ti-O-B, and Ti-B. The results demonstrate that $\mathrm{Ti}$ was present in the ceramic Ti-Al-O-B powder sample in the forms of titanium oxide, titanium borate, and titanium boride [14]. The A12p spectrum shows that the main peak centered at $74.4 \mathrm{eV}$ is in actuality the sum of three peaks: a tiny Al-B peak, an intensive Al-O-B peak, and a relatively high Al-O bond [34]. According to the findings, it can be elucidated that Al probably was found in the ceramic Ti-Al-O-B mats as the aluminum oxide, aluminum boride, and aluminum borate phases. The O1s peak is difficult to interpret because oxides and borates have O1s peaks with overlapping binding energies [15]. The main O1s peak at $531.7 \mathrm{eV}$ can be de-convoluted to three peaks concerning the O-Ti, O-Al, and OB bonds [35]. According to the area under the peaks, it can be said that oxygen had similar direct bonds with the other elements inside the Ti-Al-O-B powder. The B1s spectrum revealed 
a high peak at $192.8 \mathrm{eV}$ related to $\mathrm{B}$ in the $\mathrm{B}_{2} \mathrm{O}_{3}$ compound, a medium peak at $190.9 \mathrm{eV}$ related to $\mathrm{B}$ in aluminum borate [7], and a small peak at $187.3 \mathrm{eV}$ related to $\mathrm{B}$ in titanium borides [14]. Finally, we did not find a peak relevant to the Ti-Al binding energy, meaning that Ti and Al individually formed the ternary Ti-O-B and Al-O-B compounds inside the ceramic Ti-Al-O-B powder samples.

The binding energy spectra indicated that the oxides, borides, and borates of titanium and aluminum were candidates for the phasic composition of the nanofibrous Ti-Al-O-B powder sample. The XRD pattern of the synthesized nanofibrous TAOB-0.8 shown in Fig. 3 (a) enabled the interpretation of the composition of the Ti-Al-O-B powder. The highly peaked pattern demonstrates a complex and poly-crystalized composition for this platform. By pattern identification, it was found that the titanium had three different phases: titanium oxide, titanium borides, and titanium borate. The anatase- $\mathrm{TiO}_{2}$ (as a precursor) became exchanged with the $\mathrm{B}$ doped rutile- $\mathrm{TiO}_{2}\left(\mathrm{TiB}_{0.024} \mathrm{O}_{2}\right)$ in accordance with the 01-087-0921 JCPDS card. Diverse titanium borides, including $\mathrm{TiB}, \mathrm{TiB}_{2}$, and $\mathrm{Ti}_{2} \mathrm{~B}_{5}$, were identified considering the (01-0893922), (01-075-1045), and (00-006-0528) standard JCPDS cards. Significant peaks were attributed to the $\mathrm{TiBO}_{3}(00-017-0310)$ phase. The results also confirmed that the aluminum became crystallized in the form of $\mathrm{Al}_{2} \mathrm{O}_{3}$ (JCPDS card 00-048-0366), $\mathrm{AlB}_{2}$ (JCPDS card 00039-1483), and $\mathrm{Al}_{18} \mathrm{~B}_{4} \mathrm{O}_{33}$ (JCPDS card 00-032-0003) phases after calcination of the electrospun Ti-Al-O-B mat at $1100^{\circ} \mathrm{C}$. Therefore, it can be said that the composition of the TiAl-O-B powder consisted of oxides (e.g., B doped $\mathrm{TiO}_{2}$ and $\mathrm{Al}_{2} \mathrm{O}_{3}$ ), borides $\left(\mathrm{TiB}, \mathrm{TiB}_{2}, \mathrm{Ti}_{2} \mathrm{~B}_{5}\right.$, and $\left.\mathrm{AlB}_{2}\right)$, and borates $\left(\mathrm{TiBO}_{3}\right.$ and $\left.\mathrm{Al}_{18} \mathrm{~B}_{4} \mathrm{O}_{33}\right)$. Higher $\mathrm{B} /(\mathrm{Ti}+\mathrm{Al})$ molar ratios (1.6 and 2.4) were applied to understand the effects of the amount of B in the hybrid electrospun Ti-Al-O-B mat on the composition and morphology of the Ti-Al-O-B powder sample. The XRD patterns of the mentioned mats are presented in Fig. 3 (b and c). The results show that with increasing the $\mathrm{B}$ amount, the composition remained the same as the one described in the TAOB- 0.8 powder. However, the amount of $\mathrm{B}$ doped $\mathrm{TiO}_{2}$ and $\mathrm{Al}_{2} \mathrm{O}_{3}$ decreased, while the amounts of $\mathrm{AlB}_{2}$ and $\mathrm{Al}_{18} \mathrm{~B}_{4} \mathrm{O}_{33}$ increased. Furthermore, TiB 12 (JCPDS card; 00-052-0843) was added to the Ti-Al-O-B powder sample when the $\mathrm{B} /(\mathrm{Ti}+\mathrm{Al})$ molar ratio was adjusted to 2.4. Our findings demonstrate that no metallic phase corresponding to biphasic Al-Ti was formed in each sample when changing the $\mathrm{B} /(\mathrm{Ti}+\mathrm{Al})$ molar ratio.

For morphological comparison of the Ti-Al-O-B powders, the FESEM images shown in Fig. 4 (a to c) were examined. As seen, sintered particles with an average size of $94 \mathrm{~nm}$ were present besides larger particles (up to $275 \mathrm{~nm}$ ) in the TAOB-0.8 powder; most particles had polygonal 
and sphere-like morphology. In contrast, finer particles with needle-like morphology were observed for the powders in the TAOB-1.6 powder. In addition, the larger particles vanished, though some spherical particles remained inside the powde. According to the micrograph illustrated in Fig. 4 (b), needle-like particles with an average width of $44 \pm 5 \mathrm{~nm}$ and an average length of $113 \pm 19 \mathrm{~nm}$ were the major component of the TAOB-1.6 powder. By enhancing the $\mathrm{B} /(\mathrm{Ti}+\mathrm{Al})$ molar ratio up to 2.4 , whisker-shaped powders with an average width of $62 \pm 18 \mathrm{~nm}$ and an average length of $595 \pm 186 \mathrm{~nm}$ replaced the needle-like powders; few spherical particles were also observed.

The surface EDS spectra of all Ti-Al-O-B powders are provided as graphs in Fig. 5 (a to c). The results confirm that $\mathrm{Ti}, \mathrm{Al}, \mathrm{O}$, and $\mathrm{B}$ were the main elements of all powders. The absence of a $\mathrm{C}$ peak indicates that the PVP polymers present in the hybrid fibers were completely eliminated over calcination of the electrospun Ti-Al-O-B mat at $1100{ }^{\circ} \mathrm{C}$. Furthermore, the $\mathrm{B} /(\mathrm{Ti}+\mathrm{Al})$ molar ratios were calculated based on the atomic percent obtained via the EDS spectra. It was found that the calculated $\mathrm{B} /(\mathrm{Ti}+\mathrm{Al})$ molar ratios were $0.69,1.53$, and 2.95 in the TABO-0.8, TABO-1.6, and TABO-2.4 powders, respectively, demonstrating good estimations.

\section{Discussion}

The XPS and XRD analyses indicated that no phase corresponding to the Al-Ti, Al-Ti-O, or Al-Ti-B systems had formed. Therefore, the possible growth mechanism of the Ti-Al-O-B powder from a hybrid electrospun polymer/ceramic mat should be described based on the thermal behaviors and individual chemical reactions between the $\mathrm{TiO}_{2}-\mathrm{B}_{2} \mathrm{O}_{3}$ and $\mathrm{Al}_{2} \mathrm{O}_{3}-\mathrm{B}_{2} \mathrm{O}_{3}$ oxide systems [36]. Fig. 6 (a) presents a schematic cross-sectional view of a hybrid polymer/ceramic fiber, including an amorphous Al-O-B and $\mathrm{TiO}_{2} \mathrm{NPs}$ dissolved in the PVP matrix. The STA curves (including TG and DTA) of all mats are presented in Fig. 7 ( $a$ and $b$ ). The results show that weight loss commenced immediately at the beginning of the process. The endothermic peaks below $200{ }^{\circ} \mathrm{C}$ are attributed to the loss of structural water from boric acid and formation of the $\mathrm{H}_{2} \mathrm{~B}_{4} \mathrm{O}_{7}$ compound through Eqs. 1 and 2, respectively. The decomposition of boric acid to $\mathrm{B}_{2} \mathrm{O}_{3}$ was completed at $250{ }^{\circ} \mathrm{C}$ (Eq. 3) [18]. The solid $\mathrm{B}_{2} \mathrm{O}_{3}$ particles can distribute homogeneously within a fiber due to the homogenous nature of the electrospinning solution. During the exit of $\mathrm{H}_{2} \mathrm{O}$ vapor, micro-cracks are generated alongside the PVP matrix, facilitating PVP decomposition. Fig. 6 (b) shows the schematic processes of solid $\mathrm{B}_{2} \mathrm{O}_{3}$ formation and cracking by $\mathrm{H}_{2} \mathrm{O}$ vapor. 


$$
\mathrm{H}_{3} \mathrm{BO}_{3} \rightarrow \mathrm{HBO}_{2}+\mathrm{H}_{2} \mathrm{O}_{(\mathrm{g})}
$$

$$
\mathrm{HBO}_{2} \rightarrow \frac{1}{4} \mathrm{H}_{2} \mathrm{~B}_{4} \mathrm{O}_{7}+\frac{1}{4} \mathrm{H}_{2} \mathrm{O}_{(\mathrm{g})}
$$

$$
\frac{1}{4} \mathrm{H}_{2} \mathrm{~B}_{4} \mathrm{O}_{7} \rightarrow \frac{1}{2} \mathrm{~B}_{2} \mathrm{O}_{3(S)}+\frac{1}{4} \mathrm{H}_{2} \mathrm{O}_{(\mathrm{g})}
$$

The results of the STA analysis depicted in Fig. 7 (a and b) confirm the decomposition of $\mathrm{Al}\left(\mathrm{NO}_{3}\right)_{3}$ at $350-400{ }^{\circ} \mathrm{C}$, which is one of the vital reactions that occurred in the Ti-Al-O-B system. This is because $\mathrm{Al}_{2} \mathrm{O}_{3}$ sites are potential nuclei for the formation of aluminum boride and aluminum borate within the fibers. The schematic presentation of this phenomenon is presented in Fig. 6 (c). The decomposition of $\mathrm{Al}\left(\mathrm{NO}_{3}\right)_{3}$ took place with a weight loss of 20-30 $\%$ in all samples due to the remarkable production of the $\mathrm{NO}_{2}$ and $\mathrm{O}_{2}$ off-gases based on Eq. 4 [37].

$$
2 \mathrm{Al}\left(\mathrm{NO}_{3}\right)_{3} \rightarrow \mathrm{Al}_{2} \mathrm{O}_{3(s)}+6 \mathrm{NO}_{2(g)}+\frac{3}{2} \mathrm{O}_{2(g)}
$$

With further increase in temperature, the homogenously dispersed solid $\mathrm{B}_{2} \mathrm{O}_{3}$ became smelted at $450{ }^{\circ} \mathrm{C}$, before the molten $\mathrm{B}_{2} \mathrm{O}_{3}$ surrounded the $\mathrm{Al}_{2} \mathrm{O}_{3}$ nuclei as well as the $\mathrm{TiO}_{2} \mathrm{NPs}$ inside the fibers (Fig. 6 (d)). According to the STA analysis, with a further increase in temperature, the decomposition of PVP was intensified (Fig. 7). The PVP matrix was wholly eliminated at $600-650{ }^{\circ} \mathrm{C}$, and the initial weight of the platforms declined by approximately 78,82 , and 86 $\%$ with respect to the TAOB-0.8, TAOB-1.6, and TAOB-2.4 samples, respectively. After the PVP matrix weight residue became zero, a ceramic matrix containing solids and liquids remained throughout the fibers, as schematically presented in Fig. 6 (e). The number and nature of the solids have significant roles in solid-liquid reactions [38]. The EDS spectra confirmed the absence of the $\mathrm{C}$ element inside all powders. Above $800{ }^{\circ} \mathrm{C}$, the circumstances for the production of borides and borates are provided via the vapor-liquid-solid reactions as not only solids were covered by the molten $\mathrm{B}_{2} \mathrm{O}_{3}$, but also a matrix based on the molten $\mathrm{B}_{2} \mathrm{O}_{3}$ was formed [39]. The DTA curves in the range of 800 to $1000{ }^{\circ} \mathrm{C}$ shown in Fig. 7 (c) allowed the identification of peaks corresponding with borides and borates. Further studies were performed by the derivative of heat to temperature $\left(\mathrm{dH}_{\mathrm{dT}}{ }^{-1}\right)$ in the range of 800 to $1000{ }^{\circ} \mathrm{C}$ to understand the formation of the borides and borates. Figure 7 (d) presents the complex temperatures for assuming the formation of the boride and borate species. According to the studies, the number of exothermic peaks increased, and the heat flow intensified after increasing the $\mathrm{B} /(\mathrm{Ti}+\mathrm{Al})$ 
molar ratio. In other words, a higher amount of $\mathrm{B}_{2} \mathrm{O}_{3}$ relative to $\mathrm{Al}$ and Ti oxides promotes the formation of borides and borates. The unreacted $\mathrm{TiO}_{2}$ NPs reacted specifically with the surrounding molten $\mathrm{B}_{2} \mathrm{O}_{3}$, and thus TiB was generated according to Eq. 5 .

$2 \mathrm{TiO}_{2(s)}+\mathrm{B}_{2} \mathrm{O}_{3(L)} \rightarrow 2 \mathrm{TiB}(s)+\frac{7}{2} \mathrm{O}_{2(g)}$

The $\mathrm{O}_{2}$ gas penetrates the $\mathrm{TiO}_{2} \mathrm{NPs}$ and causes particle breakage. The broken $\mathrm{TiO}_{2} \mathrm{NPs}$, having a higher surface area, react more readily with $\mathrm{B}_{2} \mathrm{O}_{3}$. The mechanism of $\mathrm{TiO}_{2} \mathrm{NP}$ breakage is presented in Fig.6 (f), along with the mechanism of the formation of titanium boride grains inside a fiber. With higher molten $\mathrm{B}_{2} \mathrm{O}_{3}$ presence, other titanium borides such as $\mathrm{TiB}_{2}$ and $\mathrm{Ti}_{2} \mathrm{~B}_{5}$ are formed (see Eqs. 6 and 7). Following the findings of Lepakova et al. [8], it should be added that light layers of $\mathrm{Ti}_{2} \mathrm{~B}_{5}$ can appear around the previously-formed $\mathrm{TiB}_{2}$ grains. The XRD analysis indicated that an extra titanium boride $\left(\mathrm{TiB}_{12}\right)$ was also generated inside the TAOB2.4 powder. Based on reaction 8 , this titanium boride, which is highly rich in boron, was formed by the $\mathrm{B}_{2} \mathrm{O}_{3}$ compound at a higher stoichiometric ratio.

$$
\begin{aligned}
& \mathrm{TiO}_{2(s)}+\mathrm{B}_{2} \mathrm{O}_{3(L)} \rightarrow \mathrm{TiB} B_{2(s)}+\frac{5}{2} \mathrm{O}_{2(g)} \\
& 2 \mathrm{TiO}_{2(s)}+\frac{5}{2} \mathrm{~B}_{2} \mathrm{O}_{3(L)} \rightarrow \mathrm{Ti}_{2} B_{5(s)}+\frac{23}{4} \mathrm{O}_{2(g)} \\
& \mathrm{TiO}_{2(s)}+6 \mathrm{~B}_{2} \mathrm{O}_{3(L)} \rightarrow \mathrm{Ti} B_{12(s)}+10 \mathrm{O}_{2(g)}
\end{aligned}
$$

The vast amount of hot $\mathrm{O}_{2}$ gas caused the oxidation of $\mathrm{TiB}$ to $\mathrm{TiBO}_{3}$ shown in Eq. 9 [40]. The presence of titanium borate within all the powders was confirmed by both the XRD and the $2 p_{3 / 2}$ and $2 p_{1 / 2}$ peaks present in the XPS spectrum of Ti. The re-consumption of TiB in the oxidation reaction was the main reason for its low amount in the final products.

$$
T i B_{(s)}+\frac{3}{2} O_{2(g)} \rightarrow T_{i B O}(s)
$$

Notably, the reactions between the $\mathrm{Al}_{2} \mathrm{O}_{3}$ nuclei and molten $\mathrm{B}_{2} \mathrm{O}_{3}$ also took place at above 800 ${ }^{\circ} \mathrm{C}[22,32]$. The majority of the $\mathrm{Al}_{2} \mathrm{O}_{3}$ crystals were replaced with $\mathrm{Al}_{18} \mathrm{~B}_{4} \mathrm{O}_{33}$ according to Eq. 10 , and homogenously dispersed $\mathrm{Al}_{18} \mathrm{~B}_{4} \mathrm{O}_{33}$ grains were therefore created alongside the fibers (see Fig. 6 (f)). The $\mathrm{AlB}_{2}$ phase also can be synthesized directly via the reaction between $\mathrm{Al}_{2} \mathrm{O}_{3}$ nuclei and molten $\mathrm{B}_{2} \mathrm{O}_{3}$ at elevated temperature, as shown in Eq. 11, respectively [23]. The XRD patterns revealed that the amount of $\mathrm{AlB}_{2}$ was low in comparison with $\mathrm{Al}_{18} \mathrm{~B}_{4} \mathrm{O}_{33}$. This is 
because most of the $\mathrm{Al}\left(\mathrm{NO}_{3}\right)_{3}$ transformed into the $\mathrm{Al}_{2} \mathrm{O}_{3}$ nuclei, and $\mathrm{Al}_{18} \mathrm{~B}_{4} \mathrm{O}_{3}$ subsequently replaced the $\mathrm{Al}_{2} \mathrm{O}_{3}$ nuclei.

$$
\begin{aligned}
& 9 \mathrm{Al}_{2} \mathrm{O}_{3(s)}+2 \mathrm{~B}_{2} \mathrm{O}_{3(L)} \rightarrow \mathrm{Al}_{18} \mathrm{~B}_{4} \mathrm{O}_{33(s)} \\
& \mathrm{Al}_{2} \mathrm{O}_{3(s)}+2 \mathrm{~B}_{2} \mathrm{O}_{3(L)} \rightarrow 2 \mathrm{AlB} \mathrm{B}_{2(s)}+\frac{9}{2} \mathrm{O}_{2(g)}
\end{aligned}
$$

With increased temperature and the presence of more $\mathrm{B}_{2} \mathrm{O}_{3}$ within the powders, all titanium and aluminum borate and boride particles grew in size. As schematically presented in Fig. 6 (g), grain growth continued until the grains could attach well together. Intra-grain diffusion was activated at the flat grain boundaries [41], and the grown grains consequently became sintered together well by a shrinkage throughout the fiber diameter, as shown in Fig.6 (h) [42]. The sintering of borides, borates, and oxides together created the brittle fibers that may break to shorter fragments. The microscopic findings obtained from Fig. 4 (a) obviously confirm the fibrous microstructure constructed by the sintering of NPs. It is worth mentioning that although the borides have difficult sintering behavior due to the presence of strong covalent bonds [43], the nanostructured platform promoted sintering because of the high surface area to volume and the large number of particle junctions. Our findings also demonstrate that with augmentation of the $\mathrm{B} /(\mathrm{Ti}+\mathrm{Al})$ molar ratio to 1.6 , nano needle-like particles became the primary constructive agents of the powder. Grain growth in a preferred crystallography orientation is a significant specification of $\mathrm{Al}_{18} \mathrm{~B}_{4} \mathrm{O}_{33}$ [44]. The reaction between $\mathrm{Al}_{2} \mathrm{O}_{3}$ nuclei and molten $\mathrm{B}_{2} \mathrm{O}_{3}$ (Eq. 10) intensified when the $\mathrm{B} /(\mathrm{Ti}+\mathrm{Al})$ molar ratio was increased up to 2.4. In subsequence, the needlelike grain growth of $\mathrm{Al}_{18} \mathrm{~B}_{4} \mathrm{O}_{33}$ also intensified, leading to the formation of $\mathrm{Al}_{18} \mathrm{~B}_{4} \mathrm{O}_{33}$ whiskers, as confirmed by the micrographs shown in Fig. 4 (c). It is worth mentioning that not only $\mathrm{Al}_{18} \mathrm{~B}_{4} \mathrm{O}_{33}$ but also titanium borides and aluminum boride might be formed as columnar grains texture $[17,45]$. Furthermore, un-reacted $\mathrm{Al}_{2} \mathrm{O}_{3}$ nuclei may remain as the oxide phase inside the powders since the XRD patterns confirmed that the amount of aluminum oxide decreased with increased $\mathrm{B} /(\mathrm{Ti}+\mathrm{Al})$ molar ratios. Phase identification in XRD analysis showed that the un-reacted $\mathrm{TiO}_{2}$ NPs probably were doped by boron atoms at elevated temperatures. This phenomenon can be interpreted by Eq. 12 [46]. The unbroken $\mathrm{TiO}_{2} \mathrm{NPs}$ might have remained as spherical particles inside the powders. The TEM images of the Ti-Al-O-B powders obtained from different $\mathrm{B} /(\mathrm{Ti}+\mathrm{Al})$ molar ratios (Fig. 8) are in good agreement with our findings, confirming the mentioned mechanism.

$$
\mathrm{TiO}_{2(s)}+0.012 \mathrm{~B}_{2} \mathrm{O}_{3(L)} \rightarrow \mathrm{TiB}_{0.024} \mathrm{O}_{2(s)}+0.018 \mathrm{O}_{2(g)}
$$




\section{Conclusions}

Nanostructured Ti-Al-O-B powders were synthesized via the electrospinning method with different $\mathrm{B} /(\mathrm{Ti}+\mathrm{Al})$ molar ratios of $0.8,1.6$, and 2.4 . The binding energy analysis by XPS technique and phase studies by XRD analysis showed that multiple components of oxides (e.g., B doped $\left.\mathrm{TiO}_{2} ; \mathrm{Al}_{2} \mathrm{O}_{3}\right)$, borides $\left(\mathrm{TiB}, \mathrm{TiB}_{2}, \mathrm{Ti}_{2} \mathrm{~B}_{5}, \mathrm{TiB}_{12}\right.$, and $\left.\mathrm{AlB}_{2}\right)$ and borates $\left(\mathrm{TiBO}_{3}\right.$; $\left.\mathrm{Al}_{18} \mathrm{~B}_{4} \mathrm{O}_{33}\right)$ formed the nanostructured ceramic powders. With increased $\mathrm{B} /(\mathrm{Ti}+\mathrm{Al})$ molar ratios, the amounts of $\mathrm{Al}_{2} \mathrm{O}_{3}$ and $\mathrm{TiO}_{2}$ decreased, whereas the amount of $\mathrm{Al}_{18} \mathrm{~B}_{4} \mathrm{O}_{33}$ increased. The FESEM and TEM micrographs also demonstrated that the polygonal NPs $(94 \pm 41 \mathrm{~nm})$ were replaced with needle-like NPs (44 $\pm 5 \mathrm{~nm}$ wide, and $113 \pm 19 \mathrm{~nm}$ length) and nanowhiskers (62 $\pm 18 \mathrm{~nm}$ wide, and $595 \pm 186 \mathrm{~nm}$ length) when adjusting the $\mathrm{B} /(\mathrm{Ti}+\mathrm{Al})$ molar ratio to 1.6 and 2.4, respectively. The thermal behavior of electrospun Ti-Al-O-B mats indicated that the borides and borates consecutively formed by reaction with molten $\mathrm{B}_{2} \mathrm{O}_{3}$. It was found that the exit of hot gases had a significant role in the rearrangement of materials throughout the fibers. The electrospinning procedure provided an appropriate condition for the sintering of ceramic nano-arrays. Eventually, it can be concluded that electrospinning is a promising method for the fabrication of multicomponent oxide, boride, and borate nanostructures for various applications. 


\section{References}

[1]. Y. Xin, Y. Takeuchi, M. Hattori, T. Shirai, Enhanced electrical conductivity of alumina/nano-carbon ceramic composite via iodine impregnation of gel-casted alumina body and reductive sintering, J. Eur. Ceram. Soc., 39 (14) (2019) 4440-4444. https://doi.org/10.1016/j.jeurceramsoc.2019.06.002.

[2]. Y. Mazaheri, M. Meratian, R. Emadi, A. R. Najarian, Comparison of microstructural and mechanical properties of $\mathrm{Al}-\mathrm{TiC}, \mathrm{Al}-\mathrm{B}_{4} \mathrm{C}$ and $\mathrm{Al}-\mathrm{TiC}-\mathrm{B}_{4} \mathrm{C}$ composites prepared by casting techniques, Mat. Sci. Eng. A-Struct., $560(2013) \quad$ 278-287. https://doi.org/10.1016/j.msea.2012.09.068.

[3]. Z. Yu, Y. Yang, K. Mao, Y. Feng, O. Wen, R. Riedel, Single-source-precursor synthesis and phase evolution of SiC-TaC-C ceramic nanocomposites containing core-shell structured TaC@C nanoparticles. J. Adv. Ceram., 9, (2020) 320-328. https://doi.org/10.1007/s40145020-0371-z

[4]. M. Rostampour, S. Eavani, Synthesis and characterization of the novel nano composite pigments using CoWO4 on different silica sources: A comparative study, Powder Technol., 363, (2020) 86-94. https://doi.org/10.1016/j.powtec.2020.01.031.

[5]. J. Du, A.P. Sanders, V. Jindal, K.S. Ravi Chandran, Rapid in situ formation and densification of titanium boride (TiB) nano-ceramic via transient liquid phase in electric field $\begin{array}{lllllr}\text { activated } & \text { sintering, } & \text { Scripta. } & \text { Mater., } & 123 & \text { (2016) }\end{array}$ https://doi.org/10.1016/j.scriptamat.2016.06.010.

[6]. E. Salahi, H. Esfahani, I. Mobasherpour, M.A. Bijarchi, M. Taheri, Sintering behavior and mechanical properties of alumina/zirconia multilayers composite via nano-powder processing, Ceram. Int., 40 (2014) 2717-2722. https://doi.org/10.1016/j.ceramint.2013.10.051.

[7]. H. S. Song, J. Zhang, J. Lin, S. J. Liu, J. J. Luo, Y. Huang, E. M. Elssfah, A. Elsanousi, X. X. Ding, J. M. Gao, and Chengcun Tang, Coating Aluminum Borate $\left(\mathrm{Al}_{18} \mathrm{~B}_{4} \mathrm{O}_{33}\right)$ Nanowire Webs with BN, J. Phys. Chem. C, 111 (2007) 1136-1139. https://doi.org/10.1021/jp067393u

[8]. O. K. Lepakova, L. G. Raskolenko, and Yu. M. Maksimov, Titanium Borides Prepared by Self-Propagating High-Temperature Synthesis, J. Inorg. Mater., 36 (6), (2000), 568-575. Doi: 1685/00/3606-0568525.00.

[9]. B. Sarma, N.M.Tikekar, K.S.Ravi Chandran, Kinetics of growth of superhard boride layers during solid state diffusion of boron into titanium, Ceram. Int., 38 (2012) 6795-6805. https://doi.org/10.1016/j.ceramint.2012.05.077.

[10]. T. Moscicki, R. Psiuk, H. Słomińska, N. Levintant-Zayonts, D. Garbiec, M. Pisarek, P. Bazarnik, S. Nosewicz, J. Chrzanowska-Giżyńsk, Influence of overstoichiometric boron and titanium addition on the properties of RF magnetron sputtered tungsten borides, Surf. Coat. Tech., 390 (2020) 125689. https://doi.org/10.1016/j.surfcoat.2020.125689.

[11]. S.K. Mishra, V. Gokuul, S.Paswan, Alumina-titanium diboride in situ composite by selfpropagating high-temperature synthesis (SHS) dynamic compaction: Effect of compaction 
pressure during synthesis, Int. J. Refract. Met. H., 43 (2014) 19-24. https://doi.org/10.1016/j.ijrmhm.2013.10.018.

[12]. A. Ebrahimi, H. Esfahani, A. Fattah-alhosseini, O. Imantalab, In-vitro electrochemical study of $\mathrm{TiB} / \mathrm{TiB}_{2}$ composite coating on titanium in Ringer's solution, J. Alloy. Compd., 765 (2018) 826-834. https://doi.org/10.1016/j.jallcom.2018.06.312.

[13]. M. Masanta, S.M. Shariff, A. Roy Choudhury, Microstructure and properties of $\mathrm{TiB}_{2}-$ $\mathrm{TiC}-\mathrm{Al}_{2} \mathrm{O}_{3}$ coating prepared by laser assisted SHS and subsequent cladding with micro-/nano$\mathrm{TiO}_{2}$ as precursor constituent, Mater. Design, $90 \quad$ (2016) 307-317. https://doi.org/10.1016/j.matdes.2015.10.135.

[14]. J. Liu, B. Blanpain, P. Wollants, A XPS Study of Atmospheric Plasma Sprayed TiB2 Coatings, Key Engineering Materials, 368-372, (2008), 1347-1350. doi:10.4028/www.scientific.net/KEM.368-372.1347.

[15]. J. Cheng Ding, T. Fei Zhang, J. Moon Yun, K. Ho Kim, Q. Min Wang, Effect of Cu addition on the microstructure and properties of $\mathrm{TiB}_{2}$ films deposited by a hybrid system combining high power impulse magnetron sputtering and pulsed dc magnetron sputtering, Surf. Coat. Tech., 344 (2018) 441-448. https://doi.org/10.1016/j.surfcoat.2018.03.026.

[16]. K. Morsi, V. V. Patel, Processing and properties of titanium-titanium boride $\left(\mathrm{TiB}_{\mathrm{w}}\right)$ matrix composites - a review, J Mater Sci, 42 (2007) 2037-2047. https://doi.org/10.1007/s10853-006-0776-2.

[17]. Z. Jiang, W. E. Rhine, Preparation of Titanium Diboride from the Borothermic Reduction of $\mathrm{TiO}_{2}$, TiOx(OH)y, Ti(O-n-Bu)4-Derived Polymers, J. Eur. Ceram. Soc., 12 (1993) 403-411. https://doi.org/10.1016/0955-2219(93)90011-F.

[18]. M. F. Hernández, G. Suárez, M. Cipollone, M. S. Conconi, E. F. Aglietti, N. M. Rendtorff, Formation, microstructure and properties of aluminum borate ceramics obtained from alumina and boric acid, Ceram. Int., 43 (2) (2017) 2188-2195. https://doi.org/10.1016/j.ceramint.2016.11.002.

[19]. Z. Yu,N. Zhao,E. Liu,Ch. Shi,X. Du,J. Wang, Low-temperature synthesis of aluminum borate nanowhiskers on the surface of aluminum powder promoted by ball-milling pretreatment, $\quad$ Powder $\quad$ Technol., $212 \quad$ (2) $\quad$ (2011) 310315.https://doi.org/10.1016/j.powtec.2011.06.003

[20]. H. Esfahani, A. Abdollahzadeh, F. Dabir, Mahsa Rasouli Samar, Enhanced surface protection of in-738lc ni based alloy by metallic borides and aluminium borate coating via short time powder pack method, Article in Press, Protection of Metals and Physical Chemistry Of Surfaces, 56(3) (2020) 567-574. Hhtps://doi:10.1134/S2070205120030144.

[21]. H.Y. Yue, B. Wang, X. Gao, S.L. Zhang, X.Y. Lin, L.H. Yao, E.J. Guo, Effect of interfacial modifying on the microstructures, mechanical properties and abrasive wear properties of aluminum borate whiskers reinforced 6061 Al composite, J. Alloy. Compd., 692 (2017) 395-402. https://doi.org/10.1016/j.jallcom.2016.09.082. 
[22]. Y. Wang, J. Feng, Z. Wang, X. Song, J. Cao, Joining of $\mathrm{Al}_{2} \mathrm{O}_{3}$ by epitaxial growth of aluminum borate whiskers for high-temperature applications, Mater. Lett., 163 (2016) 231235. https://doi.org/10.1016/j.matlet.2015.10.079.

[23]. D. Guo, Y. Zhao, C. Ling, J. Li, H. Jin, Vacuum freeze-drying assisted preparation of spherical $\mathrm{AlB}_{2}$ powders with ultrafine microstructure, Ceram. Int., 44(6) (2018) 6451-6455. https://doi.org/10.1016/j.ceramint.2018.01.040.

[24]. S. Tautkus, K. Ishikawa, R. Ramanauskas, A. Kareiva, Zinc and chromium co-doped calcium hydroxyapatite: Sol-gel synthesis, characterization, behaviour in simulated body fluid and phase transformations, J. Solid. State. Chem., $284(2020) 121202$. https://doi.org/10.1016/j.jssc.2020.121202.

[25]. H. Wu, W. Pan, D. Lin, Electrospinning of ceramic nanofibers: Fabrication, assembly and applications. J. Adv. Ceram., 1, (2012) 2-23. https://doi.org/10.1007/s40145-012-0002-4.

[26]. A. A. Altaf, M. Ahmed, M. Hamayun, S. Kausar, M. Waqar, A. Badshah, Titania nanofibers: A review on synthesis and utilities, Inorg. Chim. Acta., 501 (2020) 119268. https://doi.org/10.1016/j.ica.2019.119268.

[27]. M.V. Someswararao, D. Pradeep, R.S. Dubey, P.S.V. Subbarao, Experimental Investigation of Electrospun Titania Nanofibers: An Applied Voltage Influence, Mater. Today: Proceedings, 18 (2019) 384-388. https://doi.org/10.1016/j.matpr.2019.06.315.

[28]. H. Esfahani, R. Jose, S. Ramakrishna, Electrospun Ceramic Nanofiber Mats Today: Synthesis, Properties, and Applications, Materials, 10(11), (2017), 1238. http://doi: 10.3390/ma10111238.

[29]. S. Osali, H. Esfahani, F. Dabir, P. Tajaslan, Structural and electro-optical properties of electrospun Cu-Doped $\mathrm{ZnO}$ thin films, Solid. State. Sci., 98, (2019), 106038. https://doi.org/10.1016/j.solidstatesciences.2019.106038.

[30]. M.P. Prabhakaran, M. Zamani, B. Felice, S. Ramakrishna, Electrospraying technique for the fabrication of metronidazole contained PLGA particles and their release profile, Mat. Sci. Eng. C-Mater., 56(1) (2015) 66-73. https://doi.org/10.1016/j.msec.2015.06.018.

[31]. H. Dai, J. Gong, H. Kim, D. Lee, A novel method for preparing ultra-fine alumina-borate oxide fibres via an electrospinning technique, Nanotechnology, 13 (2002) 674-677. https://doi.org/10.1088/0957-4484/13/5/327.

[32]. M. Ozdemir, E. Celik, U. Cocen, Effect of viscosity on the production of alumina borate nanofibers via electrospinning, Mater. Technol., 47 (2013) 735-738.

[33]. X. Song, W. Liu, S. Xu, J. Wang, B. Liu, Q. Cai, S. Tang, Y. Ma, Microstructure and elastic modulus of electrospun $\mathrm{Al}_{2} \mathrm{O}_{3}-\mathrm{SiO}_{2}-\mathrm{B}_{2} \mathrm{O}_{3}$ composite nanofibers with mullite-type structure prepared at elevated temperatures, J. Eur. Ceram. Soc., 38 (1) (2018) 201-210. https://doi.org/10.1016/j.jeurceramsoc.2017.08.007.

[34]. N. Nedfors, S. Mráz, J. Palisaitis, P. O.Å. Persson, H. Lind, S. Kolozsvari, J. M. Schneider, J. Rosen, Influence of the Al concentration in Ti-Al-B coatings on microstructure 
and mechanical properties using combinatorial sputtering from a segmented $\mathrm{TiB}_{2} / \mathrm{AlB}_{2}$ target, Surf. Coat. Tech., 364 (2019) 89-98. https://doi.org/10.1016/j.surfcoat.2019.02.060.

[35]. J. Yuan, Z. Zhang, M. Yang, F. Guo, X. Men, W. Liu, TiB 2 reinforced hybrid-fabric composites with enhanced thermal and mechanical properties for high-temperature tribological applications, Tribol. Int., 115 (2017) 8-17. https://doi.org/10.1016/j.triboint.2017.05.006.

[36]. S.A.M. Chichi, M. N. Hamidon, M. Ertugrul, M. S. Mamat, H. Jaafar, N. Aris, Influence of $\mathrm{B}_{2} \mathrm{O}_{3}$ Addition on the Properties of $\mathrm{TiO}_{2}$ Thick Film at Various Annealing Temperatures for Hydrogen Sensing. Journal of Elec Materi, 49 (2020) 33403349. https://doi.org/10.1007/s11664-020-08059-0.

[37]. J. Wang, L. Sha, Q. Yang, Y. Wang, D. Yang, Synthesis of aluminium borate nanowires by sol-gel method, Mater. Res. Bull., 40 (2005) 1551-1557.

https://doi.org/10.1016/j.materresbull.2005.04.016

[38]. V. Raghavan, Al-B-Ti (Aluminum-Boron-Titanium), J. Phase Equilib. Diff., 26(2) (2005) 173-174. http://DOI:10.1361/15477030523058.

[39]. X.F. Duan, J.F. Wang, C.M. Lieber, Synthesis and optical properties of gallium arsenide nanowires Appl. Phys. Lett. 76 (2000) 1116. https://doi.org/10.1063/1.125956.

[40]. E. Zhang, G. Zeng, S. Zeng, Oxidation behavior of in situ TiB short fibre reinforced Ti6Al-1.2B alloy in air. J. Mater. Sci., 37 (2002) 4063-4071.

https://doi.org/10.1023/A:1020019431992.

[41]. J. Zhang, F. Meng, R. I.Todd, Z. Fu, The nature of grain boundaries in alumina fabricated by fast sintering, Scripta. Mater., 62(9) (2010) 658-661. https://doi.org/10.1016/j.scriptamat.2010.01.019.

[42]. T.S. Srivatsan, G. Guruprasad, D. Black, R. Radhakrishnan, T.S. Sudarshan, Influence of TiB2 content on microstructure and hardness of $\mathrm{TiB}_{2}-\mathrm{B} 4 \mathrm{C}$ composite, Powder Technol., 159 (3) (2005) 161-167. https://doi.org/10.1016/j.powtec.2005.08.003.

[43]. G.V. Samsonov, B.A. Kovenskaya, II. The Nature of the Chemical Bond in Borides. In: Matkovich V.I. (eds) Boron and Refractory Borides. Springer, Berlin, Heidelberg, 1977.

[44]. S. C. Xu, L.D. Wang, P.T. Zhao, W. L. Li, Z. W. Xue, W. D. Fei, Fiber texture evolution of hot-rolled aluminum matrix composite reinforced by aluminum borate whisker, Mat. Sci. Eng. A-Struct., 533 (2012) 82-86. https://doi.org/10.1016/j.msea.2011.11.038.

[45]. P.H. Mayrhofer, C. Mitterer, J.G. Wen, J.E. Greene, I. Petrov, Self-organized nanocolumnar structure in superhard $\mathrm{TiB}_{2}$ thin films, Appl. Phys. Lett., 86 (2005) 131909. https://doi.org/10.1063/1.1887824.

[46]. B. Hu, Q. Zhang, L. Niu, J. Liu, J. Rao, X. Zhou, Microsphere assembly of boron-doped Rutile $\mathrm{TiO}_{2}$ nanotubes with enhanced photoelectric performance. J Mater Sci: Mater Electron, 26, (2015) 8915-8921. https://doi.org/10.1007/s10854-015-3573-3. 


\section{Figure Captions}

Fig. 1. SEM micrograph of the as-spun mat (a) and FESEM image of the nanofibrous Ti-AlO-B powder (TAOB-0.8) (b).

Fig. 2. XPS spectra of the nanofibrous Ti-Al-O-B powder (TAOB-0.8); (a) Ti2p, (b) Al2p, (c) O1s, (d) B2s scans. The black circles mark the raw intensities, the colored lines mark the deconvoluted bonds, and the black line marks the sum of the de-convoluted bonds.

Fig. 3. XRD patterns of nanofibrous Ti-Al-O-B powders with different $\mathrm{B} /(\mathrm{Ti}+\mathrm{Al})$ molar ratios: (a) TAOB-0.8, (b) TAOB-1.6, and (c) TAOB-2.4.

Fig. 4. FESEM microstructures of nanofibrous Ti-Al-O-B powders with different $\mathrm{B} /(\mathrm{Ti}+\mathrm{Al})$ molar ratios: (a) TAOB-0.8, (b) TAOB-1.6, and (c) TAOB-2.4.

Fig. 5. EDS spectra of nanofibrous Ti-Al-O-B powders with different $\mathrm{B} /(\mathrm{Ti}+\mathrm{Al})$ molar ratios: (a) TAOB-0.8, (b) TAOB-1.6, and (c) TAOB-2.4.

Fig. 6. Schematic presentation for the process of nanofibrous Ti-Al-O-B powder formation: (a) a schematic cross-section view of a hybrid polymer/ceramic fiber, including an amorphous Al$\mathrm{O}-\mathrm{B}$ and $\mathrm{TiO}_{2}$ NPs, dissolved in the PVP matrix; (b) the schematic process of solid $\mathrm{B}_{2} \mathrm{O}_{3}$ formation and cracking by $\mathrm{H}_{2} \mathrm{O}$ vapor; (c) the decomposition of $\mathrm{Al}\left(\mathrm{NO}_{3}\right)_{3}$ and potential formation of $\mathrm{Al}_{2} \mathrm{O}_{3}$ nuclei; (d) molten $\mathrm{B}_{2} \mathrm{O}_{3}$ surrounds the $\mathrm{Al}_{2} \mathrm{O}_{3}$ nuclei, and $\mathrm{TiO}_{2} \mathrm{NPs}$ solids; (e) a ceramic matrix containing solids and liquids remains throughout the fibers; (f) $\mathrm{TiO}_{2} \mathrm{NPs}$ break and boride and borate grain form; $(\mathrm{g})$ the growth of boride and borate grains; (h) the final structure of the T-A-O-B powder; sintered boride, borate, and oxide grains.

Fig. 7. (a) Thermogravimetry (TG) and (b) differential scanning calorimetry (DSC) analysis of the nanofibrous Ti-Al-O-B powders; (c) heat flow variations in the range of $800-1000{ }^{\circ} \mathrm{C}$; and (d) variations of heat derivative to temperature $(\mathrm{dH} / \mathrm{dT})$ for TABO-0.8, TAOB-1.6, and TABO2.4 in the range of $800-1000{ }^{\circ} \mathrm{C}$.

Fig. 8. TEM microstructure of Ti-Al-O-B powders with different $\mathrm{B} /(\mathrm{Ti}+\mathrm{Al})$ molar ratios: (a) TAOB-0.8, (b) TAOB-1.6, and (c) TAOB-2.4. 
Figures

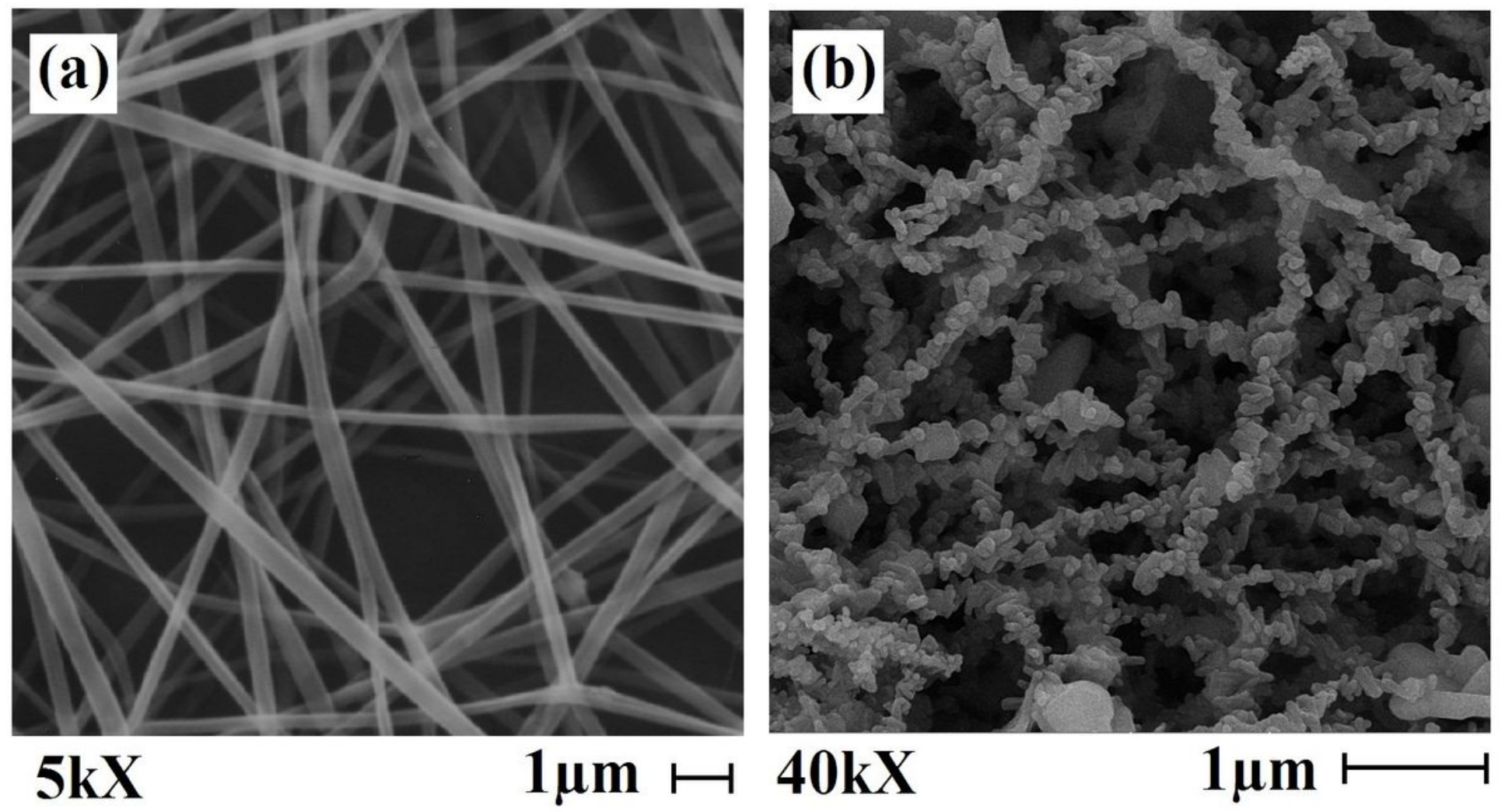

Figure 1

SEM micrograph of the as-spun mat (a) and FESEM image of the nanofibrous Ti-Al-O-B powder (TAOB0.8) (b). 

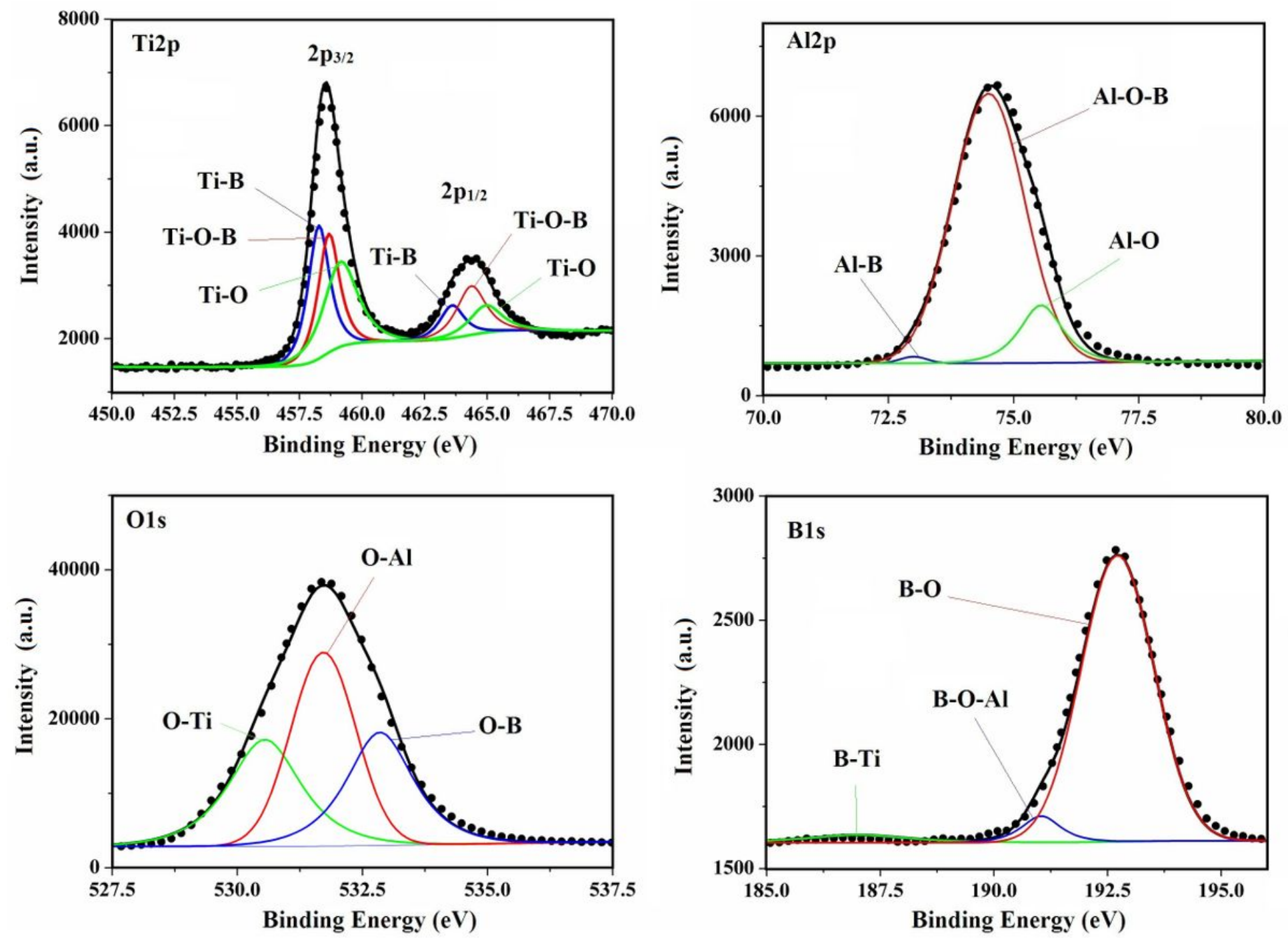

Figure 2

XPS spectra of the nanofibrous Ti-Al-O-B powder (TAOB-0.8); (a) Ti2p, (b) Al2p, (c) 01s, (d) B2s scans. The black circles mark the raw intensities, the colored lines mark the de-convoluted bonds, and the black line marks the sum of the de-convoluted bonds. 


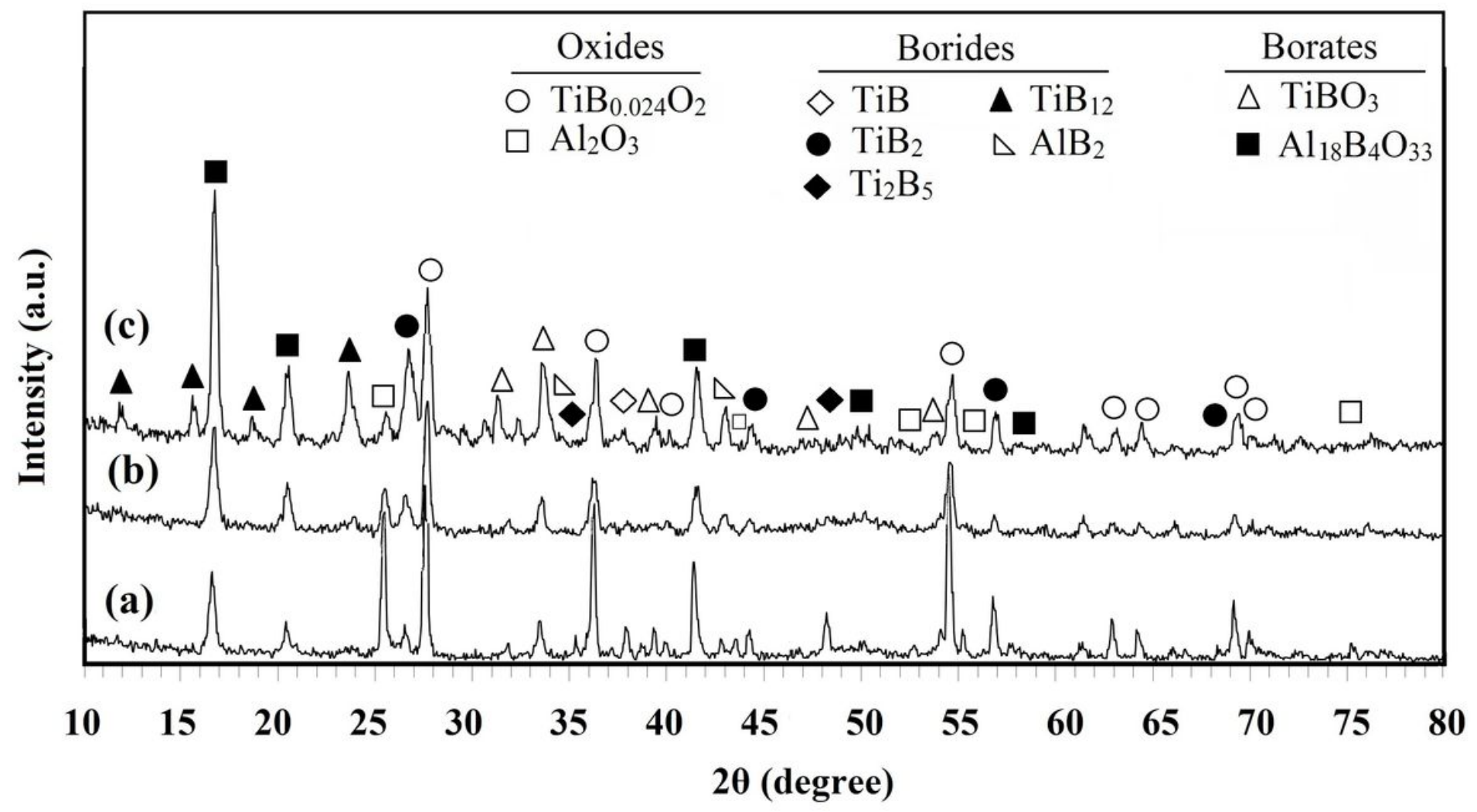

Figure 3

XRD patterns of nanofibrous Ti-Al-O-B powders with different B/(Ti+Al) molar ratios: (a) TAOB-0.8, (b) TAOB-1.6, and (c) TAOB-2.4.

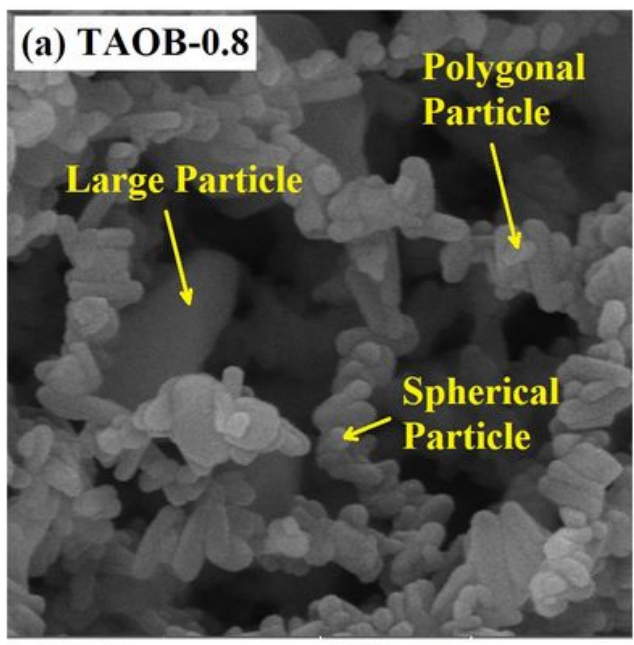

$100 \mathrm{kX}$

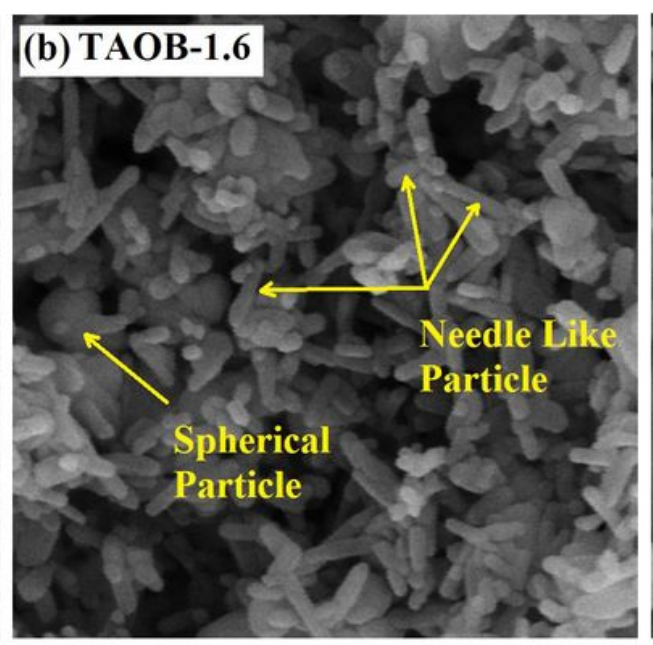

$500 \mathrm{~nm} \longmapsto 100 \mathrm{kX}$

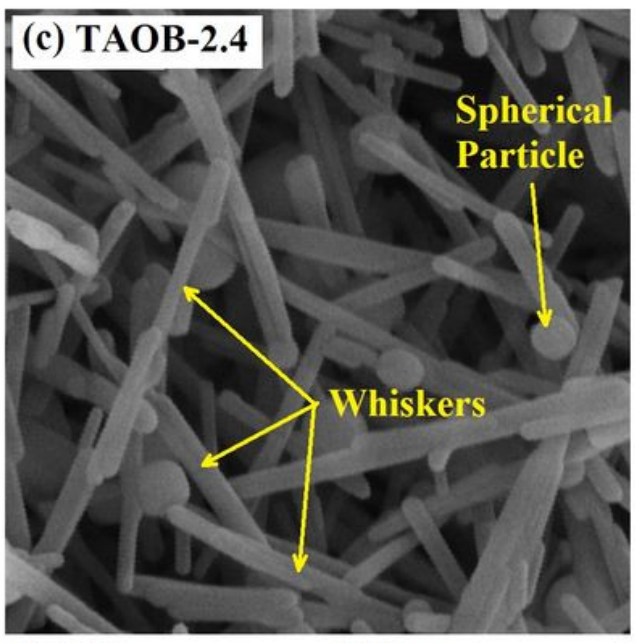

$500 \mathrm{~nm}$

Figure 4

FESEM microstructures of nanofibrous Ti-Al-O-B powders with different $\mathrm{B} /(\mathrm{Ti}+\mathrm{Al})$ molar ratios: (a) TAOB0.8, (b) TAOB-1.6, and (c) TAOB-2.4. 

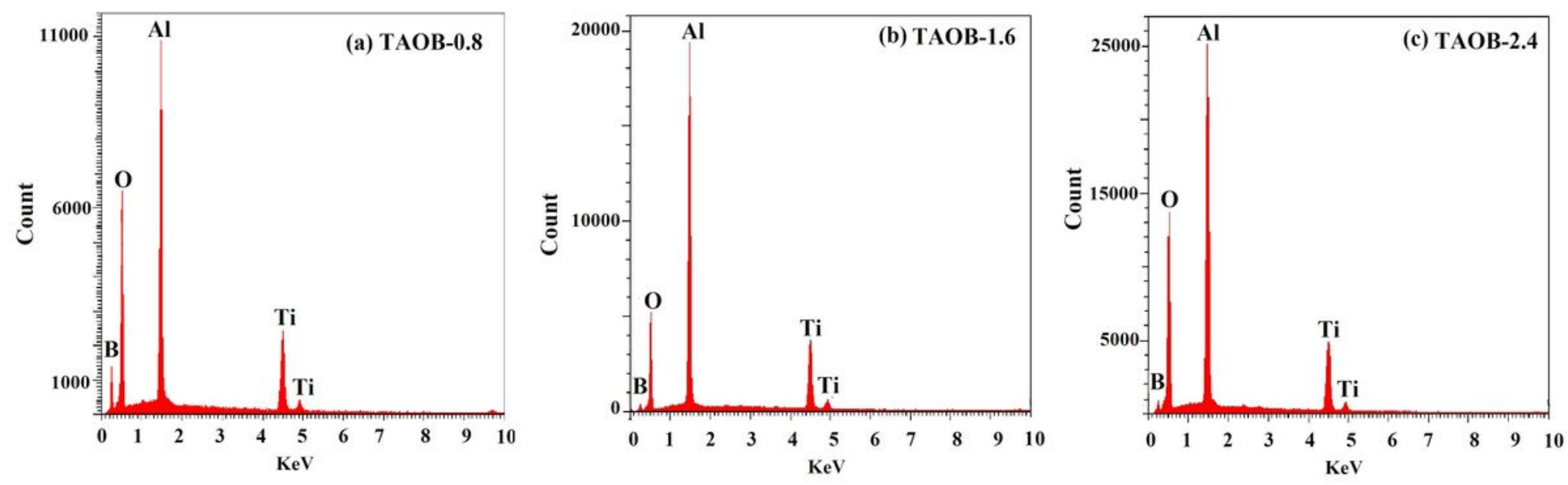

Figure 5

EDS spectra of nanofibrous Ti-Al-O-B powders with different $\mathrm{B} /(\mathrm{Ti}+\mathrm{Al})$ molar ratios: (a) TAOB-0.8, (b) TAOB-1.6, and (c) TAOB-2.4.
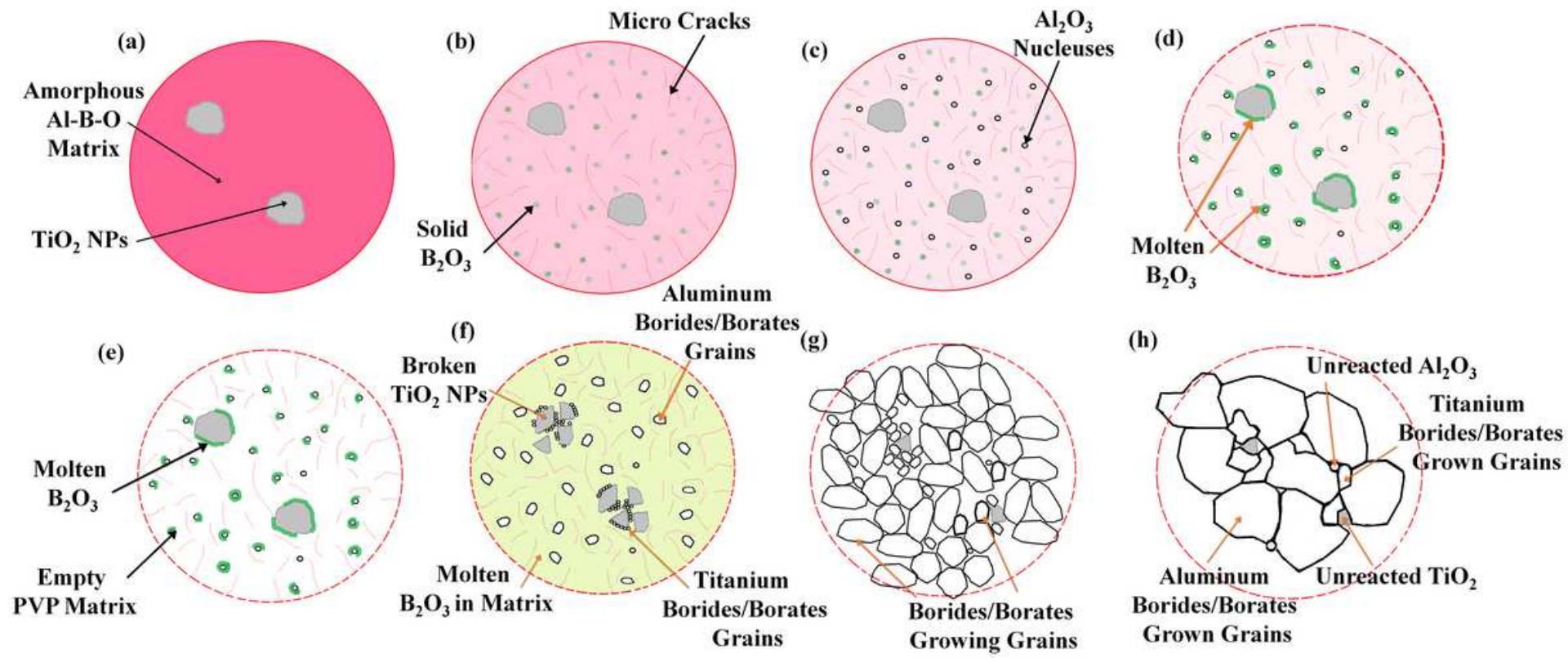

\section{Figure 6}

Schematic presentation for the process of nanofibrous Ti-Al-O-B powder formation: (a) a schematic cross-section view of a hybrid polymer/ceramic fiber, including an amorphous Al-O-B and TiO2 NPs, dissolved in the PVP matrix; (b) the schematic process of solid B2O3 formation and cracking by $\mathrm{H} 2 \mathrm{O}$ vapor; (c) the decomposition of $\mathrm{Al}(\mathrm{NO} 3) 3$ and potential formation of Al2O3 nuclei; (d) molten B2O3 surrounds the Al2O3 nuclei, and TiO2 NPs solids; (e) a ceramic matrix containing solids and liquids remains throughout the fibers; (f) TiO2 NPs break and boride and borate grain form; (g) the growth of boride and borate grains; $(\mathrm{h})$ the final structure of the T-A-O-B powder; sintered boride, borate, and oxide grains. 

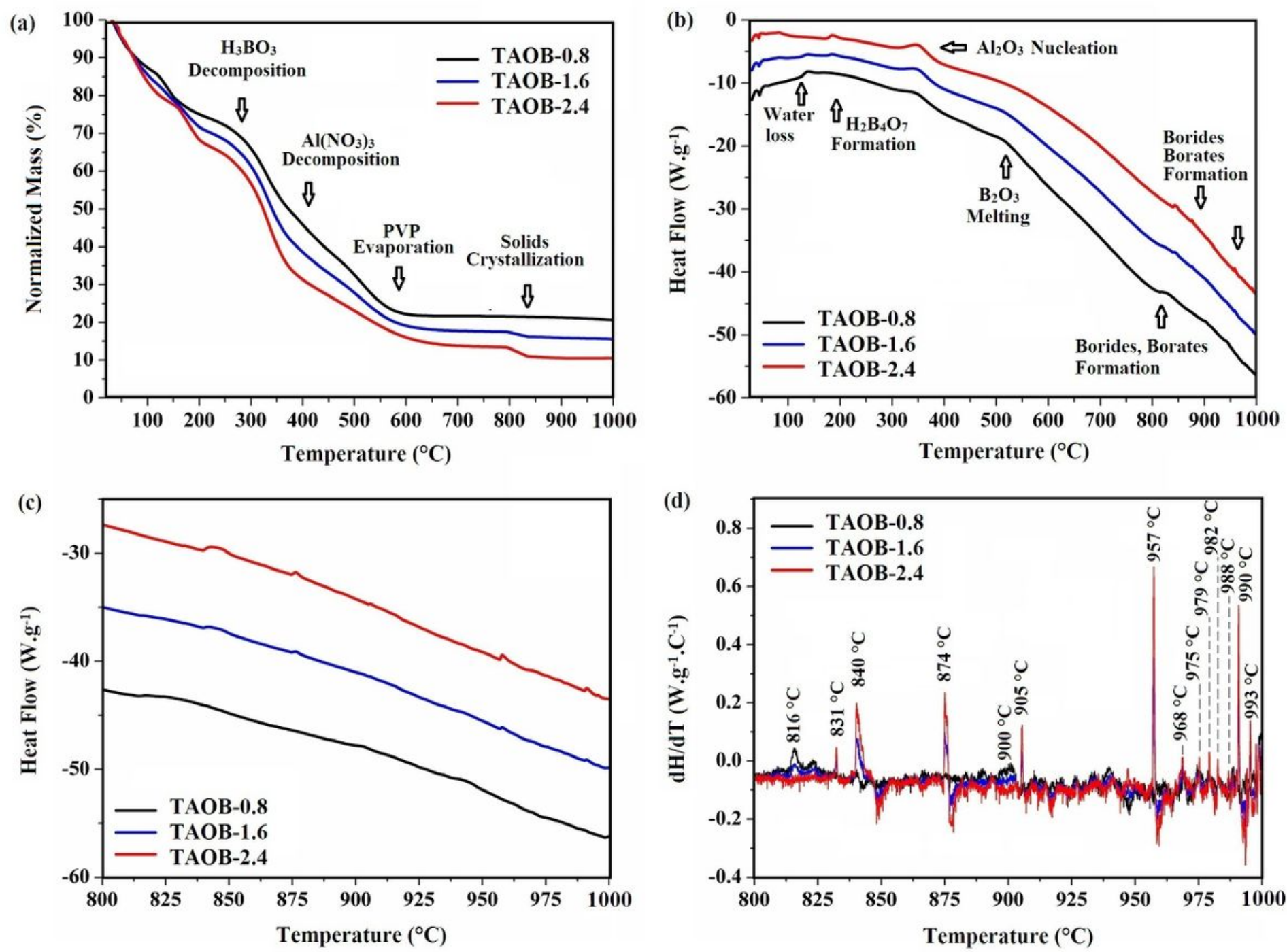

\section{Figure 7}

(a) Thermogravimetry (TG) and (b) differential scanning calorimetry (DSC) analysis of the nanofibrous Ti-Al-O-B powders; (c) heat flow variations in the range of $800-1000{ }^{\circ} \mathrm{C}$; and (d) variations of heat derivative to temperature ( $\mathrm{dH} / \mathrm{dT})$ for TABO-0.8, TAOB-1.6, and TABO-2.4 in the range of $800-1000{ }^{\circ} \mathrm{C}$.
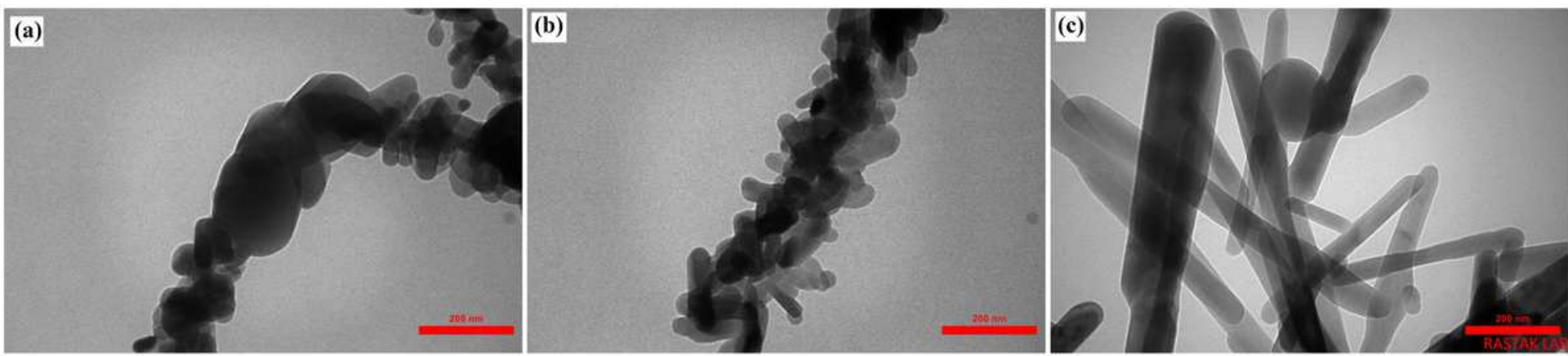

Figure 8 
TEM microstructure of Ti-Al-O-B powders with different $\mathrm{B} /(\mathrm{Ti}+\mathrm{Al})$ molar ratios: (a) TAOB-0.8, (b) TAOB-1.6, and (c) TAOB-2.4. 